$$
\begin{array}{r}
\text { ESCOL } \\
\text { COMUNIDADE QUILOMB } \\
\text { UMA INTERA } \\
\text { SOCIOCULTU } \\
\text { POR MEIO DA LEI } 10.639
\end{array}
$$




\section{ESCOLA E COMUNIDADE QUILOMBOLA: UMA INTERAÇÃO SOCIOCULTURAL POR MEIO DA LEI 10.639/03}

\section{MARTA INÊS FERREIRA LIMA}

UNIVERSIDADE FEDERAL do PARÁ

SILVANDRA CARDOSO GONÇALVES

UNIVERSIDADE FEDERAL do PARÁ 


\title{
ESCOLA E COMUNIDADE QUILOMBOLA: UMA INTERAÇÃO SOCIOCULTURAL POR MEIO DA LEI 10.639/03
}

\section{Resumo}

Este artigo é fruto de um projeto de intervenção escolar como instrumento de transformação social dentro dos princípios determinados pela Lei 10.639/2003, desenvolvido na Universidade Federal do Pará, com o tema "Escola e Comunidade Quilombola: Uma Interação Sociocultural por meio da Lei 10.639/03”. Está relacionado ao questionamento de como promover a relação sociocultural dos alunos da rede pública de ensino, com as comunidades quilombolas situadas no entorno da região metropolitana de Belém, tendo como escopo a discussão e aplicabilidade da lei na Escola Bosque Prof. Eidorfe Moreira, localizada no distrito de Outeiro, e como interface a realidade da comunidade quilombola África e Laranjituba, localizada na região de Abaetetuba.

Palavras-chave: Educação étnico-racial, Interação sociocultural Identidade e Cultura.

\section{SCHOOL AND THE QUILOMBOLA COMMUNITY: A SOCIO- CULTURAL INTERACTION THROUGH LAW 10.639/03}

\begin{abstract}
This paper is the result of a project of school intervention as an instrument of social transformation within the principles determined by Law 10.639/2003, developed at the Federal University of Pará, with the theme "School and Quilombola Community: A Sociocultural Interaction through Law 10.639/2003”. It is related to the questioning of how to promote the socio-cultural relationship of the public school students with the quilombola communities located in the surroundings of the metropolitan region of Belém, having as scope the discussion and applicability of the law in the Bosque Prof. Eidorfe Moreira School, located in the district of Outeiro, and as an interface the reality of the quilombola community Africa and Laranjituba, located in the region of Abaetetuba.
\end{abstract}

Key words: Ethnic-racial education, Sociocultural interaction, Identity e Culture. 


\section{ESCUELA Y COMUNIDAD QUILOMBOLA: UNA INTERACCI- ÓN SOCIOCULTURAL POR MEDIO DE LA LEY 10.639/03}

\section{Resumen}

Este artículo es resultado de un proyecto de intervención escolar como instrumento de transformación social dentro de los principios determinados por la Ley 10.639/2003, desarrollado en la Universidad Federal de Pará, con el tema "Escuela y Comunidad Quilombola: Una interacción sociocultural de los alumnos de la red pública de educación”, con las comunidades quilombolas situadas en la región metropolitana de Belém. Tiene como propósito discutir la aplicabilidad de la ley en la Escuela Bosque Prof. Eidorfe Moreira, localizada en el distrito de Outeiro, en diálogo con la realidad de la comunidad quilimbola África y Laranjituba, localizada en la región de Abaetetuba.

Palabras Clave: Educación étnico-racial, Interacción sociocultural, Identidad, Cultura.

Marta Inês Ferreira Lima

martalima34@gmail.com

Silvandra Cardoso Gonçalves

silvandra.1416@,hotmail.com 


\section{INTRODUÇÃO}

Este artigo é fruto de um projeto de intervenção escolar como instrumento de transformação social dentro dos princípios determinados pela Lei 10.639/2003, desenvolvido na Universidade Federal do Pará, com o tema "Escola e Comunidade Quilombola: uma Interação Sociocultural por meio da Lei 10.639/03". Tendo como finalidade sugerir uma interação sociocultural entre a Escola Prof. Eidorfe Moreira e a Comunidade Quilombola África e Laranjituba.

A escola está situada no município de Belém, no distrito industrial de Outeiro, na ilha de Caratateua. $\mathrm{O}$ distrito apresenta uma infraestrutura precária, no que diz respeito ao saneamento básico, transporte e segurança pública, pois existe uma característica de habitações estimuladas por ocupações, em meio a espaços de preservação ambiental. A fundação foi criada pela Lei $\mathrm{n}^{\circ} 7.747$ de janeiro de 1995, que depois foi alterada pela Lei Delegada $n^{\circ} 002$ de 20 de novembro do mesmo ano, iniciando suas atividades oficialmente no ano posterior.

A Escola Bosque atende 1.249 alunos mediante o sistema de ciclos da Educação Infantil, Ensino Fundamental, EJA e o Ensino Médio Técnico Integrado voltado para a Educação Ambiental. O quadro docente corresponde a 149 professores de diferentes áreas profissionais e com o objetivo de desenvolver uma educação de acordo com o que propõem o regimento da fundação.

\section{A PROBLEMÁTICA DO CENÁRIO EDUCACIONAL ATUAL E O POSI- CIONAMENTO DOCENTE PARA AS DISCUSSÕES SOBRE AS DIVERSIDA- DES CULTURAIS}

Como forma de compreender e dialogar com as problemáticas sociais em que o cenário educacional se encontra atualmente, e buscando se posicionar diante das discussões sobre as diversidades culturais, é apropriado considerar que a base para possíveis mudanças está na formação do professor, que por muito tempo, conforme (Abdias Nascimento 1978: 9), faz parte de um "sistema educacional brasileiro usado como aparelho de controle e de discriminação cultural", que construiu uma sociedade desigual na forma de pensar o outro.

A imagem do negro e do índio no Brasil é baseada em intolerâncias no comportamento social, excedentes de uma cultura eurocêntrica herdada e construída histórica e educacionalmente, destacando, segundo (Coelho 2006: 119), em seus estudos sobre os indígenas que "o perigo está em não se perceber as populações indígenas, e os índios individualmente, como agentes históricos, em toda a dimensão da expressão", tal concepção pode se estender também a vários outros grupos sociais.

Nesse sentido, o sistema educacional brasileiro tomou outros rumos, buscando a partir das Leis 10.639/03 e 11.645/08 a retomada de uma consciência sobre uma História do Brasil que não foi discutida em sala de aula. Durante o período da escravidão, um im- 
portante momento para o entendimento sobre a história do povo brasileiro, tanto os negros como os indígenas foram interpretados como objetos de propriedade; sendo assim, a sociedade condenou os negros e os índios a um futuro de invisibilidade.

Para (Slenes 2009:20) as mudanças de paradigmas, que por muito tempo guiaram as pesquisas acadêmicas, foram marcadas por um padrão europeu e americano de escrever a história do restante da humanidade.

Dessa forma, a escola hoje deve ser o caminho para desconstrução de preconceitos e discriminação racial, e reprodutora de valores, tolerância e respeito para com o outro. Mas para isso, de acordo com (Braga 2009), em citação de outro autor, "[...] é fundamental fazer com que o assunto questão racial não seja reduzido a estudos esporádicos ou unidades didáticas isoladas [...]". E sim, fazer parte das discussões rotineiras da interação entre alunos, professores, escola e currículo escolar.

Por tais questões que são necessárias mudanças nas práticas docentes, e em um "pensar" de que forma se devem trabalhara temática negra e indígena, sem que se torne uma obrigação para o professor, e sim uma conscientização da realidade social existente. Dessa forma, se devem buscaras leis, para responder as inquietações que dizem respeito às trajetórias históricas desses grupos, como sujeitos participativos dos contextos por eles vividos, nos quais corresponde a História do Brasil.

Em relação ao modelo educacional construído historicamente, por meio do qual, determinados grupos sociais são discriminados, a Lei 10.639/03trouxe um novo paradigma para os estudos que norteiam novas práticas educacionais, dentre os quais, se destacam Coelho e Soares (2015); Nascimento (1978) e Caudau \& Moreira (2003).

Como explicam (Coelho \& Soares 2015:12, apud Silva, 2013): "trata-se de uma forma pedagógica de tratar um conteúdo invisibilizado, em grande parte, pela escola, mas presente nas relações sociais de seus agentes das mais diferentes formas de apresentação.”.

São tantas as possibilidades construídas pelo professor para que a história africana e afro-brasileira esteja no cotidiano escolar, como considera (Souza 2012), "precisamos diluir essa história, que ficou por muito tempo, estagnada no contexto da escravidão". Ao desmanchá-la é possível enxergar a herança cultural africana permeada na cultura brasileira.

Mas, para isso, é necessário conhecer o continente africano, desfazendo a ideia de um continente homogêneo, e mostrando as diferenças entre as distintas partes do seu território para levar o aluno a perceber a riqueza cultural da África de maneira que evite a generalização.

Como diz Souza, para isso é necessário:

“[...] o estudo e a pesquisa como requisitos fundamentais para adquirirmos essa familiaridade $\mathrm{e}$ aprofundar o conhecimento sobre a África, e partir para uma viagem ainda desconhecida para muitos 
professores e alunos [...]" (Souza 2012:19).

Segundo (Oliva 2012), a cultura e a identidade nacionais, ditas no singular, foram substituídas por uma diversidade de práticas, ideias, padrões de comportamentos e outras definições que favorecem perceber e observar o outro pela sua diferença. É a partir desse exercício de compreender o outro, pela diferença, é que se torna brasileiro (identidade); e essas identidades que compõe a diferença, diz o mesmo autor, ficaram esquecidas quando as relações interidentitárias forçavam uma definição homogênea ou exclusiva de ser brasileiro.

Então, o debate sobre as identidades multiculturais e as relações interculturais, como observa (Oliva 2012), não é pauta dos debates no Brasil como em outros países. No entanto, são os brasileiros e africanos que se tornam debates em países afora quando são vítimas de racismo e xenofobia, e mesmo dentro de outros debates como violência e crimes. Assim, a escola deve assumir uma nova postura para lidar com esse universo cultural.

Como consideram Santos \& Cruz (2012), quando mostram que a Educação no Brasil se ocupou por muito tempo na organização da nação brasileira, o que levou na atualidade a desorganização étnica e a conflitos sociais severos.

$\mathrm{Na}$ tentativa de reverter esses conflitos sociais, a educação brasileira buscou outros caminhos. A educação das relações étnico-raciais visa contribuir com novos olhares para os estudos étnicos e principalmente novos métodos e recursos que destacam as multiplicidades das relações.

As mesmas autoras destacam ainda, possibilidades de estudos sobre a cultura africana e afro-brasileira, utilizando a noção de diáspora como noção de saída e dispersão e principalmente as relações que vão ser estabelecidas. As apropriações de diferentes culturas ressignificadas ao seu modo, e mesmo as formações de quilombos em todo Brasil.

A comunidade quilombola África e Laranjituba foi destacada para interagir junto à Escola Bosque Prof. Eidorfe Moreira, mediante o contato prévio com a mesma na ocasião da realização de estudos acadêmicos (pesquisa de campo). A comunidade foi auto definida quilombola em 2001 e titulada no ano de 2008, e está situada no município de Abaetetuba no Estado do Pará, a aproximadamente uma hora de viagem da capital belenense.

"As comunidades da região do Baixo Caeté são ainda desconhecidas por boa parte da população paraense. São comunidades quilombolas, algumas tituladas e outras em processo de titulação. Porém, a comunidade África e Laranjituba busca compartilhar com grupos de pesquisadores, escolas, acadêmicos e outros que a visitam, sua trajetória tratada com negligência pelas políticas públicas.” (Gonçalves 2015:13).

O contexto sócio espacial que o referido projeto de intervenção busca apresentar tem como maior intencionalidade promover a democratização 
do conhecimento, quando se passa a conhecer o outro.

Dessa forma, o presente artigo "Escola e Comunidade Quilombola: uma Interação Sociocultural por meio da Lei 10.639/03" pretende mostrara efetivação da lei como veículo de uma ação para a erradicação de um pensamento racista no âmbito escolar e, sobretudo, a promoção da educação étnico-racial.

Tendo como objetivo a promoção da educação étnico-racial no âmbito escolar, por meio da interação social entre escola e comunidade quilombola, buscando reduzir os índices de preconceito e discriminação racial dentro e fora do contexto escolar, fomentando a igualdade social e atendendo as determinações da Lei 10.639/03 na Escola Bosque Prof. Eidorfe Moreira.

Bem como, conscientizar alunos e professores sobre a importância do estudo sobre História e Cultura Afro-brasilei$\mathrm{ra}$, incentivando o respeito às diferenças sociais por meio do reconhecimento da atuação do grupo quilombola na sociedade, bem como, possibilitar a interdisciplinaridade como alternativa para o fortalecimento da cidadania e compreensão de eventos históricos a partir de práticas pedagógicas sistematizadas, buscando, dessa forma, a qualidade do ensino e a democratização do conhecimento.

A aplicação do projeto foi voltada para os alunos de duas turmas do $7^{\circ}$ ano $/ 9$ do Ensino Fundamental, do turno da tarde, da Escola Bosque Prof. Eidorfe Moreira.

\section{MÉTODOS PARA PRÁTICAS DO- CENTES POR MEIO DOS RECURSOS HUMANOS CULTURAIS}

A metodologia utilizada é a pesquisa bibliográfica e de campo, e essas foram pensadas de acordo com que destaca. (Candau \& Moreira 2003:159): “[...] Não se pode conceber uma experiência pedagógica 'desculturalizada', em que a referência cultural não esteja presente.".

As atividades metodológicas serão desenvolvidas durante um semestre, com início em maio e finalização em novembro do mesmo ano. As turmas realizadoras do projeto serão as do $7^{\circ}$ ano/9, sob a coordenação dos professores de História, Geografia, Sociologia e técnicos ambientais.

A estratégia metodológica se baseia no trabalho interdisciplinar que envolvendo alunos, professores e a comunidade como um todo, por meio de palestras, pesquisas, exposição, etc. Buscando uma educação significativa e consciente, como destaca Lima et al.:

"É imprescindível a busca por uma educação ambiental pautada em uma visão global, multidimensional, interdisciplinar e sistêmica, pois esta educação está intimamente associada à formação de valores e atitudes sensíveis à diversidade, à complexidade da vida, e a um sentimento de solidariedade diante dos outros e da natureza." (Lima et al. 2014:7).

De forma pedagógica, o processo de ensino e aprendizagem proposto, levará em conta também o que menciona (Dayrell 1999:156, apud Salvador 1994) sobre "aprendizagem significati- 
va: o aluno aprende quando, de alguma forma, o conhecimento se torna significativo para ele, ou seja, quando estabelece relações substantivas e não arbitrárias entre o que se aprende e o que já conhece.". Portanto, instigar os saberes dos alunos por meio de suas vivencias sociais é fundamental para as discussões em sala de aula, pois diante de uma sociedade multicultural, a escola se tornou um lugar de desafios e fomentadora das valorizações culturais.

Sendo assim, compartilhando das interações propostas do projeto entre comunidade quilombola e comunidade escolar, a instituição escolar convidará um representante quilombola para uma visita junto ao seu alunado, relatando a sua trajetória e apresentando a sua comunidade África e Laranjituba. Após o relato, os alunos realizarão uma pesquisa via internet no "blog" da comunidade, sob a responsabilidade do professor de História, com a finalidade de enriquecer as informações obtidas posteriormente pela liderança quilombola.

A próxima interação se dará com a introdução do grupo quilombola nas discussões em sala de aula com o título "Meu Quilombo não é dos Palmares, e sim um reconhecimento dele", e a partir das discussões em sala de aula, os professores de História, Geografia, Sociologia e Educação Ambiental, envolvidos na intervenção, iram propor atividades que favoreçam o aluno a compreender os quilombolas no tempo e no espaço.

O professor de História, ao discutir a temática "O Início da República", fará uma abordagem comparativa da $1^{a}$ Constituição Brasileira de 1889 (que não menciona o grupo negro) com a Constituição Brasileira de 1988 (que reconhece o grupo negro quilombola).

O professor de Geografia, ao trabalhar a temática "A Formação do Território Brasileiro", tratará da reorganização dos espaços, por meio de mapa geográfico que situe algumas comunidades quilombolas no Pará.

O professor de Sociologia, ao trabalhar a temática "Etnocentrismo e Relativismo Cultural", por meio de pesquisa retratará os hábitos culturais e a forma de organização social e econômica dos quilombolas.

O professor de Educação Ambiental, ao trabalhar as Técnicas socioambientais, por meio da visita técnica da escola à comunidade quilombola, fomentará discussões sobre produtos da biodiversidade amazônica, relacionando-os com as técnicas socioambientais quilombolas.

Como forma de compreender e valorizar as diversidades culturais que transitam no âmbito escolar, a atividade "Minha família, minha história", levando cada um aperceber um pouco dos seus referenciais culturais.

Esta atividade consiste na pesquisa, por meio de entrevista, junto aos familiares dos alunos, em que com a utilização de um questionário, estes últimos conhecerão a história das suas famílias, como elas foram compostas e as suas principais características. O questionário será constituído por temas pertinentes à composição dos membros familiares, contemplando os laços afetivos que as 
formou. A partir dos dados coletados, a turma confeccionará um mural contendo fotos de seus familiares, destacando a sua diversidade étnico-cultural, para ser apresentado em sala de aula em uma roda de conversa, e posteriormente apresentado na exposição cultural "Escola e Quilombo, uma interação sociocultural".

A quarta atividade diz respeito às características do perfil da escola e as contribuições da comunidade quilombola convidada, cujo título é: "Consciência ambiental por meio dos saberes quilombolas". Por meio de uma visita à comunidade África e Laranjituba, as turmas terão a oportunidade de conhecer as práticas e saberes quilombolas no aspecto socioambiental, para compartilhar junto à comunidade escolar as experiências vivenciadas, confeccionando, sob as orientações do técnico ambiental da própria escola, uma mini horta de acordo com os conceitos adquiridos com a referida visita.

A quinta e última atividade serão os resultados de todos os processos da interação entre escola e comunidade quilombola, com culminância da "Exposição Cultural: Escola e Quilombo, uma interação sociocultural", consistindo em uma mostra cultural, reunindo as experiências das turmas com o projeto, partindo dos eixos das quatro atividades divididas por quatro grupos. A exposição será realizada com os resultados finais das atividades propostas durante o projeto, com a participação de todos os agentes envolvidos no desenvolvimento do projeto de intervenção.
Como recursos didáticos e humanos, serão utilizados: palestra com o representante quilombola, pesquisa direcionada via internet, discussões em sala de aula e seminários em torno das atividades desenvolvidas, confecção de mural e de uma mini horta, e mostra cultural com exposição de todas as atividades desenvolvidas.

O processo avaliativo deverá considerar o aspecto "inclusivo e desvelador" (Silva 2007). Segundo Silva, todo o diálogo sistemático produzido no âmbito escolar tem como objetivo fomentar uma consciência que valorize os sujeitos no aspecto individual e coletivo, por meio de estratégias pedagógicas que fujam da rotina habitual de sala de aula, contemplado uma perspectiva de ensino-aprendizagem ressignificada.

Todas as atividades desenvolvidas pelo projeto de intervenção se darão por meio de provocações instigadas pelos docentes, com a finalidade de construir uma nova consciência capaz de tornar as relações sociais mais recíprocas.

\section{CONSIDERAÇÕES FINAIS}

Durante todo o processo de pesquisa do projeto de intervenção, alguns termos foram se consolidando e atribuindo sentidos para as práticas pedagógicas desenvolvidas. Destacam-se dois importantes conceitos para as devidas considerações.

A Educação Étnico-Racial deve ser compreendida como uma "consciência" que foi sendo construída durante o curso de especialização em Relações Étnico-Raciais para o Ensino Funda- 
mental, ofertado pelo Núcleo de Estudos e Pesquisa sobre Formação de Professores e Relações étnico-Raciais (GERA) da Universidade Federal do Pará (UFPA), como determina a Lei $10.639 / 03$, portanto, foi a partir dessa consciência étnico-racial que o presente estudo produziu práticas que criem possibilidades para visibilizar as comunidades quilombolas na sociedade, alcançando dessa forma, uma inserção por meio da interatividade entre ambas, em que possam ser conhecidas e valorizadas a sua cultura e a sua história.

Pretende-se, contudo, que a comunidade quilombola não apenas ensine os seus conhecimentos, mas que haja uma congregação de saberes no sentido de garantir os diferentes conhecimentos como pertencentes à humanidade. Assim, a escola deve oferecer aos alunos o acesso ao conhecimento sistemático, conduzido pelo conjunto da humanidade, em diferentes tempos históricos, por vários grupos sociais.

O segundo aspecto importante diz respeito à "democratização do conhecimento", colocado em prática em vários momentos durante as discussões fomentadas pelas atividades, mas principalmente quando as experiências socioculturais forem expostas e compartilhadas por todos os alunos, ou seja, quando os tradicionais conteúdos programáticos, por meio das novas estratégias de ensino, promoverem novas perspectivas de discussões e compreensões.

Tendo como finalidade a busca por um modelo a ser replicado, podendo, dessa forma, ser adaptado em outros espaços escolares por outros grupos, como: ribeirinhos, comunidades indígenas, militância negra, etc.

As possíveis modificações devem surgira partir de que o conhecimento precisa provocara reflexão e a análise da historicidade, para que cada indivíduo possa se tornar um ser consciente de seu próprio lugar no espaço social.

Por conseguinte, a valorização do indivíduo só se torna possível quando as práticas discriminatórias e preconceituosas forem combatidas por meio de estratégias pedagógicas étnico-raciais, principalmente quando a escola é o palco diário desses conflitos, que por muito tempo contribuiu para as discórdias étnicas.

E a sua utilização, sobretudo, poderá servir como um veículo de autoavaliação para permitir que os indivíduos se auto reconheçam, levando-os a refletir sobre si e o outro, propiciando a percepção da conectividade entre a diversidade cultural e a historicidade social.

\section{REFERÊNCIAS}

Baía, C. N.; R. Amorim dos Santos; R. M. N Barbosa e Silva. 2015. Educação e Diversidades na Amazônia. 2. ed. São Paulo: Ed. Livraria da Física.

Barbosa Moreira, A. F.; V. M. Canda. 2003. Educação escolar e cultura(s): construindo caminhos. Revista Brasileira de Educação 23:156-168.

Brasil, 2003. Lei $n^{\circ}$ 10.639. Diário Oficial da União de 10 de Janeiro de 2003.

Cardoso Gonçalves, S. 2015. África e Laranjituba: memória, identidade e histo- 
ricidade numa comunidade quilombola. Monografia, Departamento de História, Universidade da Amazônia, Belém-Brasil.

Cezar Coelho, M. 2006. O diretório dos índios e a chefia indígena. Campos 7(1):117134.

Dayrell, J. A escola como espaço sócio-cultural. 1999, in Múltiplos olhares sobre educação e cultura. Organizado por J. Dayrell, pp. 136-161. Belo Horizonte: Ed. UFMG.

Francisco Braga, A. 2009. Educação Afro-Indígena: caminhos para a construção de uma sociedade igualitária. Revista FACED 15:127-141.

Gonçalves e Silva, P, B. 2007. Aprender, ensinar e relacõoes étnico-raciais no Brasil. Porto Alegre/RS, ano XXX, n. 3, 489:506

Lima, M. et al. 2014. Projeto Horta na Escola: ações de educação ambiental na Escola Estadual de Ensino Fundamental Vila Nova. Universidade Federal do Pará. Belém.

Melo Souza, M, de. 2012. Algumas impressões e sugestões sobre o estudo da história da África. Revista História Hoje 1(1):17-28.

Melo Z. M. 2000. Família e Cultura: uma reflexão. Universidade Católica. Revista SymposiuM 4 ( $\mathrm{n}^{\mathrm{o}}$ especial): $72-75$

Nascimento, A. 1978. O genocídio do negro brasileiro: processo de um racismo mascarado. Rio de Janeiro: Paz e Terra.

Ribeiro Oliva, A. 2012. Entre máscara e espelhos; reflexões sobre a identidade e o ensino de história da África nas escolas brasileiras. Revista História Hoje 1(1):29-44.

Silva, M. de J. B. da. 1995. Caratateua: a ilha e o subúrbio de Belém. Dissertação de Mestrado em Geografia. Faculdade de Filosofia, Letras e Ciências Humanas, Universidade de São Paulo.

Walburga Santos, M.; A. C Juvenal Cruz. 2012. Diásporas e comunidades quilom- bolas: perspectivas metodológicas para o ensino de história da África e da cultura afro-brasileira. Revista História Hoje 1(1): 193-215.

Site:

http://funbosque.com.br/

http://quilomboafricaelaranjituba.blogspot.com.br/ 